\section{CIVILTEC}

Revista Técnico-Científica

de Engenharia Civil
Volume $2-$ n. $2-2021$

http://periodicos.unesc.net/engcivil

\title{
Influência da incorporação de resíduos reciclados de placas cerâmicas (RPC) tratados com aditivo cristalizante em argamassas
}

Doi: http://dx.doi.org/10.18616/civiltec.v2i2.6855

\author{
Maria Eduarda Gonçalves Silveira ${ }^{1}$ \\ Elaine Guglielmi Pavei Antunes ${ }^{2}$
}

\section{Introduçãa}

As placas cerâmicas mais usuais no mercado brasileiro são as do tipo Bllb (ANTUNES, 2019), pertencentes ao grupo II, placas de média absorção de água. O Centro Cerâmico do Brasil - CCB relata que, aproximadamente, $10 \%$ da produção total das placas cerâmicas Bllb são defeituosas, tornando-se resíduos, sendo crucial a sua reutilização para minorar o impacto ambiental. A construção civil também é agressiva ao meio ambiente. Em função do enorme consumo de recursos naturais, estima-se que de toda a matéria-prima produzida no mundo, de 40 a 75\% são consumidas pelo setor da construção (MATERA, 2018). Com vistas à sustentabilidade, o presente artigo tem como objetivo analisar as características no estado fresco das argamassas com substituição de $20 \%$ do agregado natural (areia) por agregado reciclado de placas cerâmicas (RPC) do tipo Bllb, tratados com aditivo cristalizante para diminuir sua absorção de água, em diferentes processos de saturação.

\section{Metodologia}

Para avaliar as características no estado fresco das argamassas com substituição parcial da areia por RPC, foi necessário caracterizá-las conforme a NBR 16916 (ABNT, 2021), quanto à absorção de água. Para inseri-los na mistura argamassada, a NBR 15116 (ABNT, 2021) recomenda a pré-molhagem dos mesmos para o ajuste das suas propriedades e minoração da absorção de água. Sendo assim, foram realizados dois diferentes tratamentos para a absorção de água. A primeira metodologia utilizada foi a pré-molhagem em uma solução líquida com $80 \%$ de água e $20 \%$ de aditivo cristalizante. Na segunda metodologia, a pré-molhagem ocorreu em uma solução líquida com com 50\% de água e 50\% de aditivo

\footnotetext{
1 Graduando em Engenharia Civil, Universidade do Extremo Sul Catarinense, mariadudinha0106@gmail.com

2 Doutora, Departamento de Engenharia Civil, Universidade do Extremo Sul Catarinense, elainegpa@unesc.net
} 


\section{CIVILTEC}

Revista Técnico-Científica

de Engenharia Civil

\section{Volume 2 - n. 2 - 2021}

http://periodicos.unesc.net/engcivil

cristalizante. A pré-molhagem para as duas metodologias tive a duração de 6 e $24 \mathrm{~h}$ de tratamento. Portanto, foram desenvolvidas cinco misturas, tendo em vista que o traço de referência empregado foi de $1: 0,25: 5,5: 0,88$, (cimento : cal : areia : a/c), e as demais com substituição de $20 \%$ da areia por RPC. A nomenclatura, dosagens e métodos de saturação podem ser visualizadas na tabela 1.

Tabela 1. Especificações das misturas. (Fonte: elaboração própria)

\begin{tabular}{lllll}
\hline Nome & Tipo de tratamento & $\begin{array}{l}\text { Tempo de } \\
\text { tratamento }\end{array}$ & $\begin{array}{l}\text { Tipo de } \\
\text { mistura }\end{array}$ & $\begin{array}{l}\text { Traço em massa } \\
\text { (cimento : cal : areia : } \\
\text { resíduo : a/c) }\end{array}$ \\
\hline ARG-REF & - & - & $100 \%$ areia & $1: 0,25: 5,5: 0: 0,88$ \\
\hline ARG-20A6 & $80 \%$ água + 20\% AC & 6 horas & & \\
ARG-20A24 & $80 \%$ água + 20\% AC & 24 horas & $\begin{array}{l}80 \% \text { areia }+ \\
\text { 20\% resíduo }\end{array}$ & $1: 0,25: 4,4: 1,1: 0,88$ \\
ARG-50A6 & $50 \%$ água $+50 \%$ AC & 6 horas & & \\
ARG-50A24 & $50 \%$ água $+50 \%$ AC & 24 horas & & \\
\hline AC - Aditivo Cristalizante & & &
\end{tabular}

Para o preparo do traço ARG-REF, foi seguido o critério de mistura da NBR 16541 (ABNT, 2016). Para o traço ARG-20A6 e ARG-50A6, a solução foi incorporada ao RPC de cada traço, deixando-os em tratamento por 6 horas. Após o tempo estipulado, os mesmos foram inseridos na argamassadeira para a produção da mistura argamassada, conforme a mesma normativa. Os traços ARG-20A24 e ARG-50A24 seguiram o mesmo mecanismo; no entanto, o tempo do processo de tratamento foi de 24 horas. As análises do comportamento no estado fresco das argamassas seguiram os ensaios estabelecidos pela NBR 13276 (ABNT, 2016), NBR 13277 (ABNT, 2005) e NBR 13278 (ABNT, 2005), para determinação do índice de consistência, da retenção de água e da densidade de massa, respectivamente.

\section{Resultados}

O agregado natural tem absorção de água de 0,66\% (NEGRINI, 2019) e o RPC resultou em uma absorção de água de 6,91\%, o que era esperado por se tratar de placas cerâmicas Bllb, que possuem absorção de água entre 6\% e 10\%, segundo a NBR ISO 13006 (ABNT, 2020).

Conforme Silva et al. (2015), quanto maior a absorção de água, maior é a porosidade do resíduo, sendo possível verificar, através do ensaio do índice de consistência, que os traços com substituição da areia por RPC sugaram mais água da mistura, tornando-as menos trabalhável. Desse modo, com a menor quantidade de água livre nas misturas, a retenção de água aumenta, logo, observa-se na figura 1, que o tratamento do RPC foi eficiente. 


\section{CIVILTEC}

Revista Técnico-Científica

de Engenharia Civil
Volume $2-$ n. $2-2021$

http://periodicos.unesc.net/engcivil

Consequentemente, os poros das misturas com RPC diminuíram, resultando numa menor densidade, como consta na figura 1.

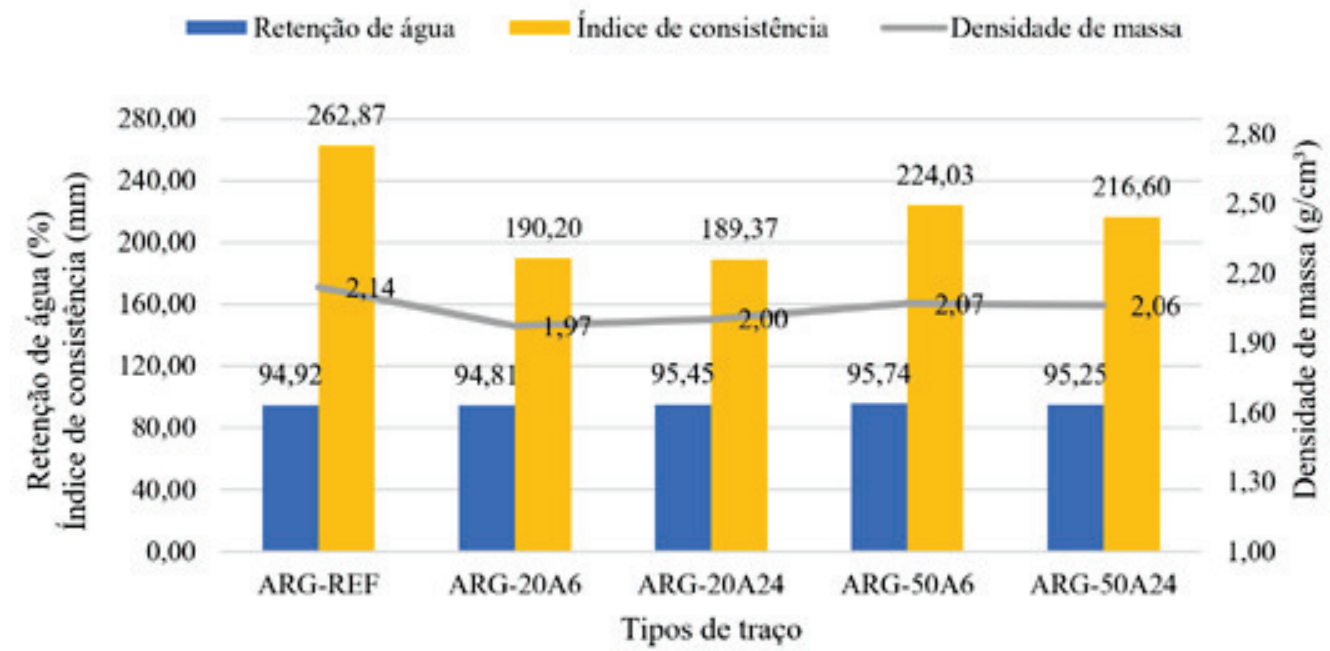

Figura 1. Resultados dos ensaios no estado fresco. (Fonte: elaboração própria)

\section{Conclusão}

O RPC absorve mais água da mistura argamassada, fazendo com que a trabalhabilidade da argamassa diminua e a retenção aumente, devido à menor quantidade de água livre na mistura. As misturas com maior quantidade de aditivo em sua solução têm valores próximos aos da mistura de referência, nas quais é possível observar a eficácia do tratamento.

Palavras-chave: Saturação. Estado Fresco. Resíduo.

\section{Referências}

ANTUNES, E. G. P. Avaliação dos efeitos da expansão por umidade (EPU) das placas cerâmicas na durabilidade dos sistemas de revestimentos cerâmicos internos. 2019. 261 f. Tese (Doutorado em Arquitetura e Urbanismo) - Curso de Pós-graduação em Arquitetura e Urbanismo, Universidade Federal de Santa Catarina. Florianópolis, 2019.

ASSOCIAÇÃO BRASILEIRA DE NORMAS TÉCNICAS. NBR 16916: agregado miúdo - determinação da densidade e da absorção de água. Rio de Janeiro. 2021. 


\section{CIVILTEC}

Revista Técnico-Científica

de Engenharia Civil
Volume $2-$ n. $2-2021$

http://periodicos.unesc.net/engcivil

ASSOCIAÇÃO BRASILEIRA DE NORMAS TÉCNICAS. NBR 15116: agregados reciclados de resíduos sólidos da construção civil - Utilização em pavimentação e preparo de concreto sem função estrutural - Requisitos. Rio de Janeiro: ABNT, 2004

ASSOCIAÇÃO BRASILEIRA DE NORMAS TÉCNICAS. NBR 13278: argamassa para assentamento e revestimento de paredes e tetos - determinação da densidade de massa e do teor de ar incorporado. Rio de Janeiro: ABNT, 2005.

ASSOCIAÇÃO BRASILEIRA DE NORMAS TÉCNICAS. NBR 13276: argamassa para assentamento e revestimento de paredes e tetos - determinação do índice de consistência. Rio de Janeiro: ABNT, 2016.

ASSOCIAÇÃO BRASILEIRA DE NORMAS TÉCNICAS. NBR 13277: argamassa para assentamento e revestimento de paredes e tetos - determinação da retenção de água. Rio de Janeiro: ABNT, 2005.

ASSOCIAÇÃO BRASILEIRA DE NORMAS TÉCNICAS. NBR 16541: argamassa para assentamento e revestimento de paredes e tetos - preparo da mistura para a realização de ensaios. Rio de Janeiro: ABNT, 2016.

ASSOCIAÇÃO BRASILEIRA DE NORMAS TÉCNICAS. NBR ISO 13006: placas cerâmicas - definições, classificação, características e marcação. Rio de Janeiro: ABNT, 2020.

CENTRO CERÂMICO DO BRASIL (CCB). Programa Setorial da Qualidade de Placas Cerâmicas para Revestimento: relatório setorial 035/2020. Disponível em: <https://www.ccb.org.br/pt/psq> Acesso em: 30 abr. 2021.

MATERA, M. O desafio e construir de forma sustentável. 2018. Disponível em: <https:// ecogranito.com.br/blog/desafiodeconstruir>. Acesso em: 28 mar. 2021.

NEGRINI, J. G. Análise da influência da substituição parcial de agregado miúdo natural por resíduos de placas cerâmicas com distintos tratamentos de saturação em argamassas. 2019. 22 f. TCC (Graduação) - Curso de Engenharia Civil, Universidade do Extremo Sul Catarinense - Unesc, Criciúma, 2019.

SILVA, M. N. P.; SILVA, M. N. P.; BARRIONUEVO, B. de U. S.; FEITOSA, I. M.; SILVA, G. S. (2015). Revestimentos cerâmicos e suas aplicabilidades. Caderno de Graduação - Ciências Exatas E Tecnológicas, Maceió, v. 2, n. 3, p. 87-97, maio 2015 - UNIT - ALAGOAS, 2(3), 87-97. 